\title{
$1(86) / 2017$
}

INFORMATSIONNO-

UPRAVLIAIUSHCHIE SISTEMY

REFEREED EDITION

(INFORMATION

AND CONTROL SYSTEMS)

Founder

"Information and Control Systems», Ltd.

Publisher

Saint-Petersburg State University

Saint-Petersburg State Universit

Editor-in-Chief

M. Sergeev

Dr. Sc., Tech., Professor, St. Petersburg, Russia

Deputy Editor-in-Chief

E. Krouk

Dr. Sc., Tech., Professor, St. Petersburg, Russia

Executive secretary

O. Muravtsova

Editorial Council

C. Christodoulou

PhD, Professor, Albuquerque, New Mexico, USA

L. Chubraeva

RAS Corr. Member, Dr. Sc., Tech., Professor, St. Petersburg, Russia L. Fortuna

PhD, Professor, Catania, Italy

A. Fradkov

Dr. Sc., Tech., Professor, St. Petersburg, Russia

Dr. Kozlov

B. Meyer

Dr. Sc., Professor, Zurich, Switzerland

A. Ovodenko

Dr. Sc., Tech., Professor, St. Petersburg, Russia

Y. Podoplyokin

Dr. Sc., Tech., Professor, St. Petersburg, Russia

RAS Academician, Dr. Sc., Phys.-Math., Novosibirsk, Russia

V. Simakov

Dr. Sc., Tech., Professor, Moscow, Russia

V. Vasilev

RAS Corr. Member, Dr. Sc., Tech., Professor, St. Petersburg, Russia R. Yusupov

RAS Corr. Member, Dr. Sc., Tech., Professor, St. Petersburg, Russia

Editorial Board

V. Anisimov

Dr. Sc., Tech., Professor, St. Petersburg, Russia

B. Bezruchko

Dr. Sc., Phys.-Math., Saratov, Russia

N. Blaunstein

Dr. Sc., Phys.-Math., Professor, Beer-Sheva, Israe

A. Dudin

Dr. Sc., Tech., Professor, Minsk, Belarus

Dumer

PhD., Professor, Riverside, USA

V. Khimenko

Dr. Sc., Tech., Professor, St. Petersburg, Russia

G. Maltsev

Dr. Sc., Tech, Professor, St. Petersburg, Russia

G. Matvienko

Dr. Sc., Phys.-Math., Professor, Tomsk, Russia

V. Melekhin

Dr. Sc., Tech., Professor, St. Petersburg, Russia

A. Shalyto

Dr. Sc., Tech., Professor, St. Petersburg, Russia

A. Shelupanov

Dr. Sc., Tech., Professor, Tomsk, Russia

A. Shepeta

Dr. Sc., Tech., Professor, St. Petersburg, Russia

A. Smirnov

Dr. Sc., Tech., Professor, St. Petersburg, Russia

Z. Yuldashev

Dr. Sc., Tech., Professor, St. Petersburg, Russia

A. Zeifman

Dr. Sc., Phys.-Math., Vologda, Russia

Editor: A. Larionova

Proofreader: T. Zvertanovskaia

Design: A. Koleshko, M. Chernenko

Layout and composition: J. Umnitsina

Contact information

The Editorial and Publishing Center, SUAI

67, B. Morskaia, 190000, St. Petersburg, Russia

Website: http://i-us.ru/en, E-mail: ius.spb@gmail.com

Website: http://i-us.ru/

The Journal was registered in the Ministry of Press,

Broadcasting and Mass Media of the Russian Federation.

Registration Certificate JD № 77-12412 from April, 19, 2002.

Re-registration in the Federal Service for Supervision in the Sphere of Telecom,

Information Technologies and Mass Communications (ROSKOMNADZOR)

due to change of the founder: "Information and Control Systems", Ltd.,

JD № FS77-49181 from March, 30, 2012

(c) Corporate authors, 2017

THEORETICAL AND APPLIED MATHEMATICS

Balonin N. A., Sergeev M. B. Ryser's Conjecture Expansion

for Bicirculant Strictures and Hadamard Matrix Resolvability

by Double-Border Bicycle Ornament

INFORMATION PROCESSING AND CONTROL

Bogachev I. V., Levenets A. V., Chye En Un. Statistical Analysis

of Telemetry Data for Compression

SYSTEM AND PROCESS MODELING

Tatarnikova T. M. Analytical-Statistical Model of Mesh Network

Survivability Evaluation

Kharchenko A. V., Ushakov I. A. Model of Ground-Space Command

Information Network with Data Path Formation under External

Interference on Radio Channels

23

HARDWARE AND SOFTWARE RESOURCES

Kopkin E. V., Borod'ko D. N., Pastukhova K. E. Algorithm

for Constructing a Quasi-Optimal Flexible Program for Analysis

of Technical State of an Object

Molev A. A. XML-based Method for Automatic Formation of Telecommu

nication Modules of Structural Elements in Automated System

31

40

\section{INFORMATION CODING AND TRANSMISSION}

Sulavko A. E., Eremenko A. V., Tolkacheva E. V., Borisov R. V.

Complexation of Independent Biometric Features in People Recognition

with Quadratic Forms, Perceptrons and Functional Hee-module

Mitrofanov S. A. Overview of Broadcast Transmission usage Scenarios in LTE Networks

INFORMATION CHANNELS AND MEDIUM

Hadar Ofer, Bronfman Irina, Blaunstein Nathan. Optimization of

Error Concealment based on analysis of Fading Types. Part 1. Statistical

Description of the Wireless Video Channel, Models of BER Determination and Error Concealment of Video Signals

Martynova L. A. Concerted Action of a Radiator and Autonomous

Uninhabited Submersibles for Effective Seismic Exploration

SYSTEM ANALYSIS

Zhilnikova N. A., Shishkin A. I., Epifanov A. B., Epifanova M. A.

Algorithm of Control over Technogenic Impact Distribution for Territorial

Natural-Technical Complex based on Geoinformation Systems

93

CONTROL IN MEDICAL AND BIOLOGICAL SYSTEMS

Khafizov $\boldsymbol{R}$ G. Khafizov D. G. Tanaeva E. G. Algorithm of Parameter

Estimation and Vessel Tracking on Eye Fundus Images

CONTROL IN SOCIAL AND ECONOMIC SYSTEMS

Chertovskoy V. D. Mathematical Description and Computer Realization

of Adaptive Automatized Company Control System Model

Submitted for publication 09.01.17. Passed for printing 20.02.17. Format $60 \times 84$ Phototype SchoolBookC. Digital printing

Layout original is made at the Editorial and Publishing Center, SUAI.

67, B. Morskaia, 190000, St. Petersburg, Russia

Pinted from slides at the Editorial and Publishing Center, SUA. 


\section{$1(86) / 2017$}

\section{РЕЦЕНЗИРУЕМОЕ ИЗДАНИЕ}

\section{ИНФОРМАЦИОННО- УПРАВЛЯЮЩИЕ СИСТЕМЫ}

Учредитель

ООО «Информационно-управляющие системы»
Издатель

Санкт-Петербургский государственный университет

аэрокосмического приборостроения

Главный редактор

М. Б. Сергеев,

д-р техн. наук, проф., С.-Петербург, РФ

Зам. главного редактора

д-р техн. наук, проф., С.-Петербург, РФ

Ответственный секретарь

О. В. Муравцова

Редакционный совет:

Председатель А. А. Оводенко,

д-р техн. наук, проф., С.-Петербург, РФ

В. Н. Васильев

чл.-корр. РАН, д-р техн. наук, проф., С.-Петербург, РФ

В. Н. Козлов,

Д-р техн. наук, проф., С.-Петербург, РФ

К. Кристодолу,

д-р наук, проф., Альбукерке, Нью-Мексико, США

Б. Меиер,

д-р наук, проф., Цюрих, Швейцария

Ю. Ф. Подоплёкин

Д-р техн. наук, проф., С.-Петербург, РФ

В.В. Симаков,

д-р техн. наук, проф., Москва, РФ

Л. Фортуна,

Д-р наук, проф., Катания, Италия

А. Л. Фрадков,

Д-р техн. наук, проф., С.-Петербург, РФ

Л.И. Чубраева

чл.-корр. РАН, д-р техн. наук, С.-Петербург, РФ

Ю. И. ШОКИН

акад. РАН, д-р физ.-мат. наук, проф., Новосибирск, РФ

Р. М. Юсупов

чл.-корр. РАН, д-р техн. наук, проф., С.-Петербург, РФ

Редакционная коллегия:

В.Г. Анисимов,

д-р техн. наук, проф., С.-Петербург, РФ

Б. П. Безручко,

д-р физ.-мат. наук, проф., Саратов, РФ

Н. Блаунштейн,

д-р физ.-мат. наук, проф., Беэр-Шева, Израиль

А. Н. Дудин

д-р физ.-мат. наук, проф., Минск, Беларусь

И. И. Думер,

д-р наук, проф., Риверсайд, США

А. И. Зейфман,

д-р физ.-мат. наук, проф., Вологда, РФ

Г. Н. Мальцев,

д-р техн. наук, проф., С.-Петербург, РФ

Г. Г. Матвиенко

д-р физ.-мат. наук, проф., Томск, РФ

В.Ф. Мелехин

д-р техн. наук, проф., С.-Петербург, РФ

А. В. Смирнов,

д-р техн. наук, проф., С.-Петербург, РФ

В.И. Хименко,

д-р техн. наук, проф., С.-Петербург, РФ

А. А. Шалыто,

д-р техн. наук, проф., С.-Петербург, РФ

А. А. Шелупанов,

д-р техн. наук, проф., Томск, РФ

А. П. Шепета,

д-р техн. наук, проф., С.-Петербург, РФ

3. М. Юлдашев,

д-р техн. наук, проф., С.-Петербург, РФ

Редактор: А. Г. Ларионова

Корректор: Т. В. Звертановская

Дизайн: М. Л. Черненко

Компьютерная верстка: Ю. В. Умницына

Адрес редакции: 190000 , Санкт-Петербург,

Б. Морская ул., д. 67, ГУАП, РИЦ

Тел.: (812) 494-70-02, e-mail: ius.spb@gmail.com, сайт: http://i-us.ru

Журнал зарегистрирован в Министерстве РФ по делам печати,

телерадиовещания и средств массовых коммуникаций.

Свидетельство о регистрации ПИ № 77-12412 от 19 апреля 2002 г.

Перерегистрирован в Роскомнадзоре.

Свидетельство о регистрации ПИ № ФС77-49181 от 30 марта 2012 г.

Журнал входит в «Перечень ведущих рецензируемых научных журналов и изданий, в которых должны быть опубликованы основные научные результаты диссертации на соискание ученой степени доктора и кандидата наук».

๑) Коллектив авторов, 2017
ТЕОРЕТИЧЕСКАЯ И ПРИКЛАДНАЯ МАТЕМАТИКА

Балонин Н. А., Сергеев М. Б. Расширение гипотезы Райзера

на двуциклические структуры и разрешимость матриц Адамара орнаментом в виде бицикла с двойной каймой

ОБРАБОТКА ИНФОРМАЦИИ И УПРАВЛЕНИЕ

Богачев И. В., Левенец А. В., Чье Е. У. Статистический анализ

телеметрических данных сточки зрения задачи сжатия

МОДЕЛИРОВАНИЕ СИСТЕМ И ПРОЦЕССОВ

Татарникова Т. М. Аналитико-статистическая модель

оценки живучести сетей с топологией mesh

Харченко А. В., Ушаков И. А. Модель наземно-космической

командно-информационной сети с формированием маршрута

передачи данных в условиях внешних помеховых воздействий на радиоканал

ПРОГРАММНЫЕ И АППАРАТНЫЕ СРЕДСТВА

Копкин Е. В., Бородько Д. Н., Пастухова К. Е. Алгоритм построения

квазиоптимальной гибкой программы анализа технического

состояния объекта

Молев А. А. Метод автоматического формирования

телекоммуникационных модулей структурных элементов

автоматизированных систем на основе XML-описания

КОДИРОВАНИЕ И ПЕРЕДАЧА ИНФОРМАЦИИ

Сулавко А. Е., Еременко А. В., Толкачева Е. В., Борисов Р. В.

Комплексирование независимых биометрических признаков

при распознавании субъектов на основе сетей квадратичных форм,

персептронов и меры Хи-модуль

Митрофанов С. А. Обзор сценариев использования

широковещательной передачи в сетях LTE

ИНФОРМАЦИОННЫЕ КАНАЛЫ И СРЕДЫ

Hadar Ofer, Bronfman Irina, Blaunstein Nathan. Optimization of Error

Concealment based on analysis of Fading Types. Part 1. Statistical

Description of the Wireless Video Channel, Models of BER Determination

and Error Concealment of Video Signals

Мартынова Л. А. Метод согласованного поведения излучателя

и автономных необитаемых подводных аппаратов для эффективного ведения сейсморазведки

СИСТЕМНЫЙ АНАЛИЗ

Жильникова Н. А., Шишкин А. И., Епифанов А. В., Епифанова М. А.

Алгоритм управления перераспределением техногенной нагрузки для территориальных природно-технических комплексов на основе геоинформационных систем

УПРАВЛЕНИЕ В МЕДИЦИНЕ И БИОЛОГИИ

Хафизов Р. Г., Хафизов Д. Г., Танаева Е. Г. Алгоритм оценки

102

УПРАВЛЕНИЕ В СОЦИАЛЬНО-ЭКОНОМИЧЕСКИХ СИСТЕМАХ

Чертовской В. Д. Математическое описание и компьютерная

реализация модели адаптивной автоматизированной системы управления производством

СВЕДЕНИЯ ОБ АВТОРАХ параметров и прослеживания сосудов на изображениях глазного дна 